\title{
Changes in the Activities of the Trunk Muscles in Different Kinds of Bridging Exercises
}

\author{
Yong Soo $\mathrm{KonG}^{1)}$, Yong Ho $\mathrm{CHO}^{2)}$, Ji Won PARK ${ }^{1)^{*}}$ \\ 1) Department of Physical Therapy, College of Medical Science, Catholic University of Daegu: 13-13 \\ Hayang-ro, Hayang-eup, Gyeongsan-si, Gyeongbuk 712-702, Republic of Korea \\ 2) Department of Physical Therapy, Kyungbuk College, Republic of Korea
}

\begin{abstract}
Purpose] The purpose of this study was to examine the effects of different types of bridging exercises on the activities of the trunk muscles. [Methods] Twenty-four students participated in this experiment. The activities of the internal oblique (IO), external oblique (EO), rectus abdominis (RA), and erector spinae (ES) muscles were measured in four different bridging exercises. [Results] There were significant differences in the IO, EO, RA, and ES among the four kinds of bridging exercise. The activities of IO, EO and RA were the highest in prone bridging (exercise 4), followed by unilateral bridging (exercise 3), and supine bridging on balance pads (exercise 2). In conventional bridging (exercise 1), the activities of IO, EO, and RA were the lowest. The activity of ES was the highest in exercise 3 followed by exercises 2 and 1. The activity of ES was the lowest than in exercise 1. [Conclusions] Bridging exercise in the prone position may be a more effective method of enhancing trunk muscle activities exercises in other positions.
\end{abstract}

Key words: Bridge exercise, Muscle activity, EMG

(This article was submitted Jun. 11, 2013, and was accepted Jul. 3, 2013)

\section{INTRODUCTION}

The stability of the spine depends on co-activation of the trunk muscles. Co-activation of these muscles is necessary in programs aimed at treating and preventing lumbar pain $^{1-3)}$. To stabilize the spine, harmonious coordination of all of the trunk muscles is crucial, rather than activation of a particular muscle ${ }^{3)}$. Adjusting the co-ordination of global and local muscles maintains the stability of the spine ${ }^{2,4)}$ The trunk muscles are anatomically classified into global muscles and local muscles. The global muscles largely generate strength and are involved in overall stabilization of the trunk, and the local muscles are involved in segmental trunk stabilization ${ }^{5}$. The stabilization of the trunk is necessary for the stability of the spine and the pelvis when they are in a functional position, to increase stability during movement, to enhance muscle strength, and to adjust muscle movements and balance ${ }^{6)}$.

The principal trunk stabilization exercises are pelvic tilt exercises, quadruped exercises, abdominal hollowing exercises, and bridging exercises ${ }^{7)}$. Among these, the aim of bridging exercises is to make lumbar pain patients feel more comfortable by reducing their pain and retraining their global and local muscles to ensure they are coordinated in

*Corresponding author. Ji Won Park (E-mail: mylovept@, cu.ac.kr)

(C2013 The Society of Physical Therapy Science

This is an open-access article distributed under the terms of the Creative Commons Attribution Non-Commercial No Derivatives (by-ncnd) License $<$ http://creativecommons.org/licenses/by-nc-nd/3.0/> . an appropriate manner ${ }^{4)}$. Berkefors et al. ${ }^{8)}$ reported that the use of a deep abdominal muscle training method enhanced the activity of the deep muscles. Akuthota and Nadler ${ }^{9}$ stressed the importance of core strengthening of the lumbar area in different positions. Exercise on an unstable surface increases the co-contraction of the muscles and the stability of the trunk $\mathrm{k}^{10)}$, and prompts postural adjustment and balance more than exercise on a stable surface ${ }^{11)}$. In addition to methods which gradually increase the intensity of trunk stabilization exercises, there are methods which increase the intensity of the resistance and the intensity of the exercise. Such methods heighten the degree of instability on a support surface using a treatment ball, a vestibular balance plate, or a form roller ${ }^{12)}$.

Bridging exercise is a method which is often used clinically, and much research has been conducted using diverse methods and modifications. Recently, attention has focused on changes in the activities of the trunk muscles during bridging exercises, and many studies have attempted to identify an efficient method of enhancing the activities of the trunk muscles. The conventional bridging exercise is conducted in a supine position, and most are other exercises are modifications of this exercise. To the best of our knowledge, very little research of prone bridging exercises has taken place. Accordingly, this study investigated the effect of different types of bridging exercise (in prone and supine positions) on the activities of the trunk muscles.

\section{SUBJECTS AND METHODS}

Twenty-four subjects participated in this study (males: 13, females: 11), and their average age, height, and weight 


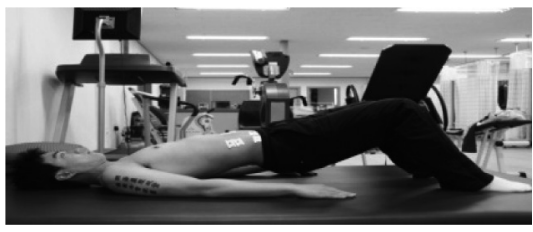

Fig. 1. Supine bridging exercise

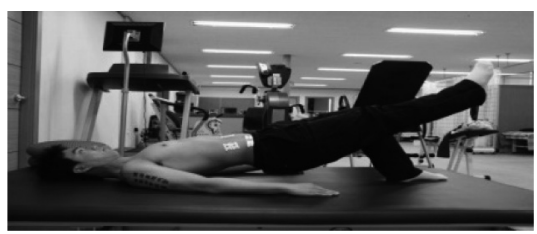

Fig. 3. Unilateral bridging exercise

were $21.38 \pm 1.64$ years, $167.71 \pm 7.55 \mathrm{~cm}$, and $60.04 \pm$ $9.22 \mathrm{~kg}$, respectively. The subjects were students at the department of physical therapy of Y University. None of the subjects had complained of pain in the musculoskeletal region during the previous six months, and none had orthopedic or neurological disease. Prior to participation, all participants were required to read and sign an informed consent form, in accordance with the ethical standards of the Declaration of Helsinki. The protocol for this study was approved by the local ethics committee.

Four kinds of bridging exercise were conducted in the experiment.

Exercise 1 (supine bridging): In the starting position of the bridging exercise in the supine position, the subjects bent their knee joints at 90 degrees and spread both arms at about 30 degrees, with both hands on the ground. They kept their head and neck in a straight position, with their eyes looking at the ceiling (Fig. 1).

Exercise 2 (supine bridging on balance pads): The subjects adopted the same position as that of exercise 1 , but they placed their feet on TOGU balance pads (Fig. 2).

Exercise 3 (unilateral bridging): Again, adopting the same position as that of exercise 1 , the subjects raised their dominant-side leg (Fig. 3).

Exercise 4 (prone bridging on the elbows and toes): In a prone position, the subjects bent their elbows at 90 degrees and supported their bodies with their forearms and toes, with their neck slightly extended and their eyes looking to the front (Fig. 4).

To reduce errors while performing the different exercises, the subjects adopted a neutral position, with the pelvis raised. The researcher stood at the side to ensure that the subjects adopted the correct position. Prior to the exercises, the subjects were also advised how to conduct the exercises. A dynamic air cushion (TOGU, Germany) was used for the unstable support surface. The subjects performed the exercises in a random manner by selecting a closed envelope containing the name of the exercise to be performed. The subjects started each exercise on the command of "Start" and took a rest of 5 minutes after each exercise to prevent

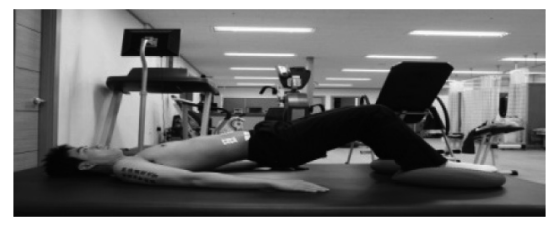

Fig. 2. Supine bridging exercise on TOGU

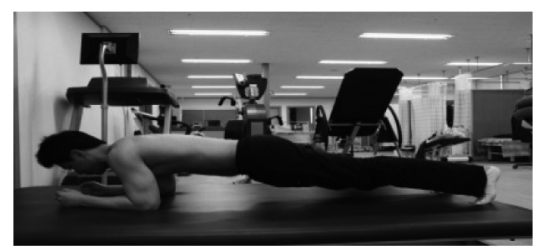

Fig. 4. Prone bridging exercise on the elbows and toes

muscle fatigue.

A surface electromyography system (Telemyo 2400TG2, Noraxon, USA) was used to measure the activities of the trunk muscles. To reduce the skin's resistance prior to the application of $\mathrm{Ag} / \mathrm{Ag}-\mathrm{Cl}$ (Biopac, diameter $2 \mathrm{~cm}$ ) electrodes to the subjects' bodies, their skin was shaved to remove hair from the area where the electrodes would be attached. The surface of their skin was then cleaned with absorbent cotton, which was sterilized by soaking in alcohol, before the electrodes were attached along the direction of the muscle fibers. The ground electrode was placed on the anterior superior iliac spine (ASIS) of the dominant side.

To measure the muscle activities of the subjects in the different exercise positions, the electrodes were attached to four muscles: $3 \mathrm{~cm}$ lateral to the umbilicus for the rectus abdominis (RA); midway between the anterior iliac spine and symphysis pubis and above the inguinal ligament for the internal oblique muscle (IO); $15 \mathrm{~cm}$ lateral to the umbilicus for the external oblique muscle (EO); and $2 \mathrm{~cm}$ lateral to the $\mathrm{L} 2$ spinous process for the erector spinae $(\mathrm{ES})^{13)}$. The electrodes were attached to the dominant side muscles of the subjects. The surface electromyography signals were digitized and processed using the MR-XP program on a personal computer. The sampling rate of the surface electromyography signals was $1024 \mathrm{~Hz}$. Signals were band-pass filtered between 20 and $500 \mathrm{~Hz}$, and full-wave rectified. The root mean square (RMS) of the values was calculated.

To standardize the action potential of each muscle, the maximal voluntary isometric contraction (MVIC) was used. MVIC measurement positions were adopted following a previous study ${ }^{14)}$. Each position was held for $7 \mathrm{sec}$ onds to reduce measurement variation at the start and end points of the exercise. The activity of the muscles was measured for 5 seconds, excluding the first and last second. The collected data were statistically processed using SPSS 18 PASW Statistics, and the averages and standard deviation of the general characteristics of the subjects were calculated. Repeated one-way analysis of variance was used to determine changes in the activities of the muscles in the different 
Table 1. Comparison of the activities of the muscles in different types of bridge exercises (Unit: \%MVIC)

\begin{tabular}{ccccc}
\hline & IO & EO & RA & ES \\
\hline Exercise 1 & $7.88 \pm 6.01^{*}$ & $8.27 \pm 7.04^{*}$ & $4.09 \pm 2.46^{*}$ & $48.05 \pm 43.97^{*}$ \\
Exercise 2 & $9.26 \pm 7.01^{*}$ & $9.98 \pm 7.87^{*}$ & $4.72 \pm 3.01^{*}$ & $54.62 \pm 46.80$ \\
Exercise 3 & $17.37 \pm 15.18^{*}$ & $23.49 \pm 18.77^{*}$ & $9.46 \pm 8.04^{*}$ & $64.58 \pm 76.73$ \\
Exercise 4 & $57.54 \pm 35.77^{*}$ & $37.38 \pm 30.95^{*}$ & $46.98 \pm 30.10^{*}$ & $9.52 \pm 9.13^{*}$ \\
\hline
\end{tabular}

${ }^{*} \mathrm{p}<0.05, \dagger \mathrm{IO}$ : internal oblique, EO: external oblique, RA: rectus abdominis, ES: erector spinae

types of exercises. Within-individual analysis and withinsubject contrast were used to detect changes in the activity of the muscles in the various types of exercises. Statistical significance was accepted for values of $\mathrm{p}<0.05$.

\section{RESULTS}

There were significant differences in \% MVICs of the IO, EO, RA, and ES $(\mathrm{p}<0.05)$ among the exercises, and the patterns of increase of muscle activities of the muscles, except ES, were consistent across the exercises. The activities of IO, EO and RA were the highest in exercise 4, followed by exercise 3 and exercise 2 . The activities of IO, EO, and RA were the lowest in exercise 1. Different from other muscles, the activity of ES was the highest in exercise 3 followed by exercise 2 and 1 . The activity of ES was the lowest in exercise 4 (Table 1).

\section{DISCUSSION}

Recent research has focused on the evaluation of the activities of the trunk muscles in bridging exercises. This study was conducted to determine more efficient methods for increasing the activities of the trunk muscles in different types of exercises. The results reveal there were significant differences among the four exercise methods in the activities of the IO, EO, RA, and ES muscles. In exercise 4, the activities of the RA, EO, and the IO muscles were higher than in exercises 1, 2, and 3. Overall, the activity of the ES was high in exercises 1,2 , and 3, and the activity of the ES was the lowest in exercise 4 . The appropriate activation of local muscles and interactions between local muscles and global muscles are necessary to ensure functional stability ${ }^{15)}$. It has also been reported that bridging exercises with the feet on an unstable surface, like a Swiss ball, induce higher muscle activities than the same exercises with the feet on a stable surface. Accordingly, bridging exercises with the feet on unstable surface are effective at increasing dynamic balance, especially for the prevention of spinal damage $^{2)}$. Kavcic et al. ${ }^{16)}$ reported that bridging exercise with the right leg lifted was very closely associated with the activity of the RA in the side bridging exercise when healthy adults performed lumbar stabilization exercise. The detection of high IO, EO, and RA activity in the present study suggests that exercise 4 mobilizes more muscle fibers in the trunk than the other exercises. Our results also show that the trunk muscle activity in exercise 4 was the highest followed by exercise 3 , then exercise 2 , while the trunk muscle activity in exercise 1 was the lowest.
Exercise 4 is similar to a push-up exercise, but the subjects' elbows are used for support rather than their hands. Thus, the motion is easier than a push-up motion. The pushup motion is a closed-chain exercise, and it has been employed to enhance the balance of the proprioceptors and to increase the activity of the shoulder muscles ${ }^{17)}$.

Meyer ${ }^{18)}$ noted that the EO has a spiral form. It is connected to the serratus anterior muscle through the fascia, and the connection ring causes the EO to contract during push-up motions. Maenhout et al. ${ }^{19)}$ also reported that the connection of the muscles to the fascia affects the activities of the IO and the EO, thereby increasing the mobilization of the muscle fibers.

Ludewig et al. ${ }^{20)}$ observed that the load on a subject's upper arms may be reduced when the elbows support the subject's weight. Thus, the exercise position may be maintained for a longer time, and it is easier for patients to perform the exercise in rehabilitation.

The results of the present study suggest that the position adopted in exercise 4 is useful for lowering the activity of the ES and increasing the activity of the IO, EO, and RA. As bridging exercise in a prone position reduces the base of support, the subject's elbows and feet support the weight in the distal part. Therefore, in the process of overcoming instability, the activities of the muscles increase in response to biophysical demands.

This study had some limitations. The subjects were healthy young adults in their 20 s, making it difficult to generalize the results to the general population. For clinical applications, research with patients who have symptoms and pain is necessary.

\section{REFERENCES}

1) Lehman GJ, Hoda W, Oliver S: Trunk muscle activity during bridgin exercises on and off a Swissball. Chiropr Osteopat, 2005, 13: 14-21. [Medline] [CrossRef]

2) Marshall PW, Murphy BA: Core stability exercises on and off a swiss ball. Arch Phys Med Rehabil, 2005, 86: 242-249. [Medline] [CrossRef]

3) Stevens VK, Bouche KG, Mahieu NN, et al.: Trunk muscle activity in healthy subjects during bridging stabilization exercises. BMC Musculoskelet Disord, 2006, 7: 75. [Medline] [CrossRef]

4) Stevens VK, Coorevits PL, Bouche KG, et al.: The influence of specific training on trunk muscle recruitment patterns in healthy subjects duringstabilization exercises. Man Ther, 2007, 12: 271-279. [Medline] [CrossRef]

5) Bergmark A: Stability of the lumbar spine. A study in mechanical engineering. Acta Orthop Scand Suppl, 1989, 230: 1-54. [Medline]

6) Richardson CA, Snijders CJ, Hides JA, et al.: The relation between the transverses abdominis muscle, sacroiliac joint mechanics, and low back pain. Spine, 2002, 27: 399-405. [Medline] [CrossRef]

7) Hubley-Kozey CL, Vezina MJ: Muscle activation during exercises to improve trunk stability in men with low back pain. Arch Phys Med Rehabil, 2002, 83: 1100-1108. [Medline] [CrossRef] 
8) Bjerkefors A, Ekblom M, Josefsson K, et al.: Deep and superficial abdominal muscle activation during trunk stabilization exercises with and without instruction to hollow. Man Ther, 2010, 15: 502-507. [Medline] [CrossRef]

9) Akuthota V, Nadler SF: Core strengthening. Arch Phys Med Rehabil, 2004, 85: S86-S92. [Medline] [CrossRef]

10) Vera-Garcia FJ, Grenier SG, McGill SM: Abdominal muscle response during curl-ups on both stable and labile surfaces. Phys Ther, 2000, 80: 564-569. [Medline]

11) Karthikbabu S, Nayak A, Vijayakumar K, et al.: Comparison of physio ball and plinth trunk exercises regimens on trunk control and functional balance in patients with acute stroke: a pilot randomized controlled trial Clin Rehabil, 2011, 25: 709-719. [Medline] [CrossRef]

12) Hall CM, Brody LT: Therapeutic Exercise; Moving toward function, 1st ed. Philadelphia: Lippincott Williams \& Wilkins, 1999.

13) Carm JR, Kasman GS, Holtz J: Introduction to Surface Electromyography. Maryland: Aspen, 1998, pp 360-374

14) Kendall FP, McCreary EK, Provance PG: Muscles; testing and function with posture and pain, 5th ed. Philadelphia: Lippincott Williams \& Wilkins, 2005, pp 165-219.
15) Hodges PW, Moseley GL: Pain and motor controlofthe lumbopelvic region: effect and possible mechanisms. J Electromyogr Kinesiol, 2003, 13: 361-370. [Medline] [CrossRef]

16) Kavcic N, Grenier S, McGill SM: Quantifying tissue loads and spine stability while performing commonly prescribed low back stabilization exercises. Spine, 2004, 29: 2319-2329. [Medline] [CrossRef]

17) Lehman GJ, Danielle G, Ushma P: An unstable support surface does not increase scapulothoracic stabilizing muscle activity during push up and push up plus exercises. Man Ther, 2008, 13: 500-506. [Medline] [CrossRef]

18) Meyers TW: Anatomy trains. Myofascial meridians for manual an movement therapists. New York: Churchill Livingstone, 2001, p 280.

19) Maenhout A, Praet KV, Pizzi L, et al.: Electromyographic analysis of knee push up plus variations: what is the influence of the kinetic chain on scapular muscle activity? Br J Sports Med, 2010, 44: 1010-1015. [Medline] [CrossRef]

20) Ludewig PM, Hoff MS, Osoeski EO, et al.: Relative balance of serratus anterior and upper trapezius muscle activity during push-up exercises. Am J Sports Med, 2004, 32: 484-493. [Medline] [CrossRef] 